\title{
High strength stainless steel 14301 for prestressed concrete structures protection
}

\author{
M.C. Alonso, M. Sánchez, E. Mazario, F.J. Recio, H. Mahmoud \& R. Hingorani \\ Institute "Eduardo Torroja" of Construction Sciences, Madrid. Spain
}

\begin{abstract}
High Strength Stainless Steels (HSSS) are being developed with the aim to improve corrosion resistance of prestressed concrete structures in aggressive environments. In the present paper focus is given to mechanical and corrosion performance of a HSSS type 14301. The ability of passivation in alkaline media and the risk of local corrosion (pitting) in presence of chlorides, has been determined. Besides, the response of the stainless steel submitted to mechanical strains similar to those in service is considered with respect to the risk of corrosion, Stress Corrosion Cracking (SCC) and Hydrogen Embrittlement (HE). The cold-drawn HSSS 14301 shows higher tolerance to chloride ion than conventional prestressing steel. The local corrosion becomes significant for chloride contents above $0.75 \mathrm{M}$. The applied load moves pitting corrosion initiation at lower concentrations of chlorides. The pitting enhances risk for SCC developing, although the steel is more resistance to $\mathrm{HE}$ in comparison with conventional presstressing steel.
\end{abstract}

\section{INTRODUCTION}

The use of high strength stainless steel for prestressing concrete can be considered an alternative to increase the durability of these type of structures in highly polluted chloride media, like marine environment or when using de-icing salt in cold climates. During the last five years effort has been made in order to analyse the corrosion performance of this type of high strength steels for their use as prestressing tendons or wires with bond in concrete (Alonso et al. 2007, Alonso et al. 2009, Nürnberger et al. 2008, Wu 2009,). Although some practical experience exists concerning the use of high strength stainless steel, for instance in ground anchors (Mietz 2001), the understanding of corrosion behaviour in direct contact with aggressive environments (atmosphere) under high stresses makes the knowledge gained up to know insufficient in prestressing concrete.

Meanwhile, the use of stainless steel (SS) as reinforcement to enhance the service life of concrete structures has been more widely studied, most of the effort being concentrated on evaluating the increase of corrosion resistance in chloride environments. The high corrosion resistance of stainless steel in alkaline media is primarily attributed to the high resistance oxide layers formed on its surface. The resistance of the passive film is determined by the alloy composition, the medium, and the conditions in which it is generated, causing the passivation of the stainless steel to be a very complex process (Abreu et al. 2004, Veleva et al. 2002). Stainless steel reinforcements were first used many decades ago and have proved their ability to avoid corrosion problems for a very long time, even in very aggressive conditions (Castro et al. 2002). Hence, the use of stainless steel reinforcements is now considered a very reliable method for ensuring long term durability of reinforced concrete structure when exposed to extreme conditions. However, their use has been limited due to their higher cost compared with carbon steel. Although a complete cost estimation of the service life of structures leads to the conclusion that the higher prime cost may be compensated by a longer lifetime and a reduction of maintenance costs (Klingghofer et al. 2000, Knudsen et al. 1998). 
With respect to corrosion performance, main knowledge was gained from test done with 304 and 316 SS as reinforcemen, which have shown a very high corrosion resistance (Bautista et al. 2007, Escudero et al. 2002, Garcia-Alonso et al. 2007, Hewitt et al. 1994, Nürnberger et al. 1996, Sorensen et al. 1990). The passive film formed in these austenitic stainless steels is stable, invisible, thin, durable and extremely adherent in alkaline environments. Although austenitic stainless steels show a very high corrosion resistance in a wide variety of aggressive environments, they can suffer pitting corrosion in chloride environments, (Bautista et al. 2007, Sorensen et al. 1990). It is well known that $\mathrm{Cl}$ ions are aggressive enough to attack stainless steel and initiate pitting (Fossati et al. 2006, Abd el Meguid et al. 2000, Ameer et al. 2004).

However, due to the lower tensile strength of stainless steels reinforcements $\left(\sigma_{\max }=500-600 \mathrm{Mpa}\right)$ they can not fulfill the necessary requirements for prestressing structures where tensile strengths of $1700 \mathrm{Mpa}$ or more are attained. This apparent limitation may be dealt with by carrying out a colddrawing process. However, few results have been published until now concerning such high strength stainless steels (Nürnberger et al. 2008, Wu et al. 2009, Alonso et al. 2007).

The aim of the present work is to evaluate the mechanical properties and corrosion performance of an austenitic stainless steel high strength type 1.4301 (304) in chloride environments and in alkaline simulated concrete pore environments with respect its interest as pretesting wire embedded in concrete.

\section{EXPERIMENTAL PROCEDURE}

High strength stainless steel 14301 wires have been used in the present study. The industrial production process was as follows: A parent stainless steel wire with $9 \mathrm{~mm}$ diameter was submitted to a cold-drawing process up to reaching the desired mechanical strength. The final wire diameter was $3.5 \mathrm{~mm}$. Later on, the high strength wire was machined to produce a rib of $0.2 \mathrm{~mm}$. The aspect of the 14301 HSSS wire is shown in Figure 1. The chemical composition is that included in Table 1.
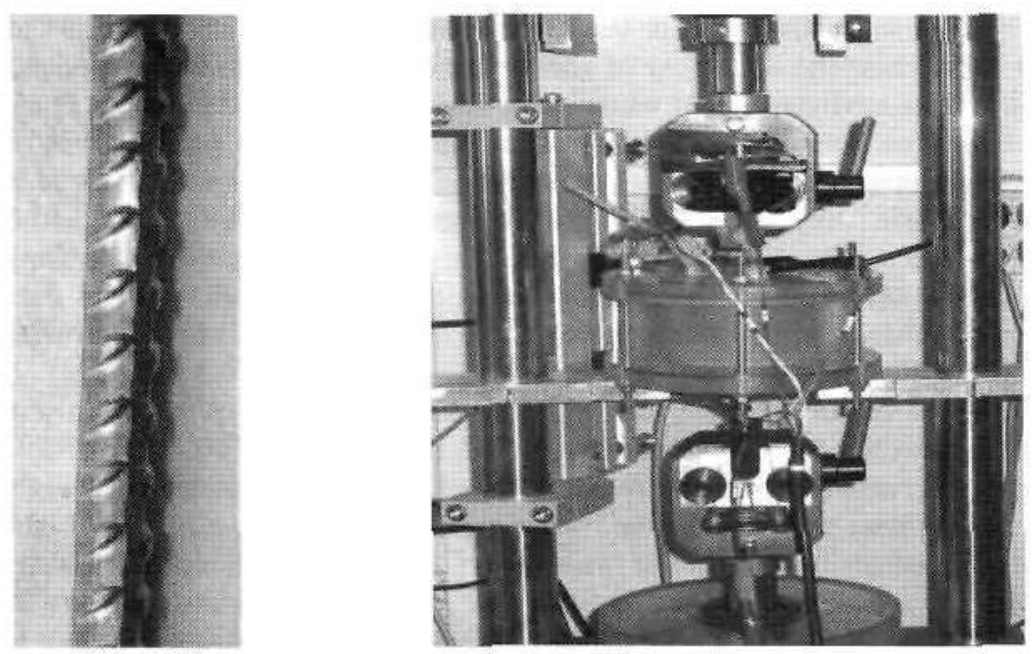

Figure 1. High strength stainless steel wire, 1.4301, left. Equipment for mechanical and corrosion tests under load, right.

Table 1. Chemical composition of high strength stainless steel 1.4301 .

\begin{tabular}{lllllll}
\hline & $\mathrm{C}$ & $\mathrm{Si}$ & $\mathrm{Mn}$ & $\mathrm{Cr}$ & $\mathrm{Ni}$ & $\mathrm{Mo}$ \\
\hline $\begin{array}{c}\mathrm{SS}-(14301) \\
(304)\end{array}$ & $0.057 \pm 0.004$ & 0.389 & 1.136 & $18.5 \pm 0.1$ & $8.48 \pm 0.005$ & 0.25 \\
\hline
\end{tabular}


The capability of passivation of HSSS-14301 when exposed to alkaline media has been evaluated by ciclo-voltametries tests. Furthermore, slow strain-rate tensile tests have been carried out in order to examine corrosion risk of these HSSS wires. The mechanical properties of cold-drawn HSSS were determined following the standard ISO6892:1998. Finally, the relaxation behaviour was examined according to (UNE-ISO 15630-3).

\section{RESULTS AND DISCUSSION}

\subsection{Influence of cold-drawing process in the microstructure and mechanical properties}

The initial microstructure of the parent 14301, given in Figure 2-left, shows grains with polygonal shape characteristic of austenitic stainless steels with high $\mathrm{Ni}$ content. The grains do not have any preferential orientation neither in transversal nor in longitudinal direction. After a severe cold-drawing process the well defined geometry of the grains disappears, forming a more refined, martensitic microstructure, characterized by small needles. A deformation of the grain in the direction of cold-drawing is also observed.

The changes in the microstructure may induce changes in the corrosion performance of the cold-drawn stainless steel with respect to that of the parent steel. In fact some authors consider that the transformation of austenitic to martensitic microstructure contributes to increase the susceptibility to SCC and HE phenomena when working under service load conditions (Chen et al. 2003, Wu et al. 2009).

A cold-drawing degree of $89 \%$ was applied to obtain the mechanical properties of the 14301 steel shown in Table 2. The obtained yield and tensile strength of the wires is considered to be high enough to allow for an application as prestressing steel.

The isothermal relaxation of the prestressing HSSS steel wire due to stress loss of an initially loaded specimen (initial load $=70 \%$ of the tensile strength) is shown in Figure 3 as a function of time. For comparison purpose the relaxation behaviour of conventional cold
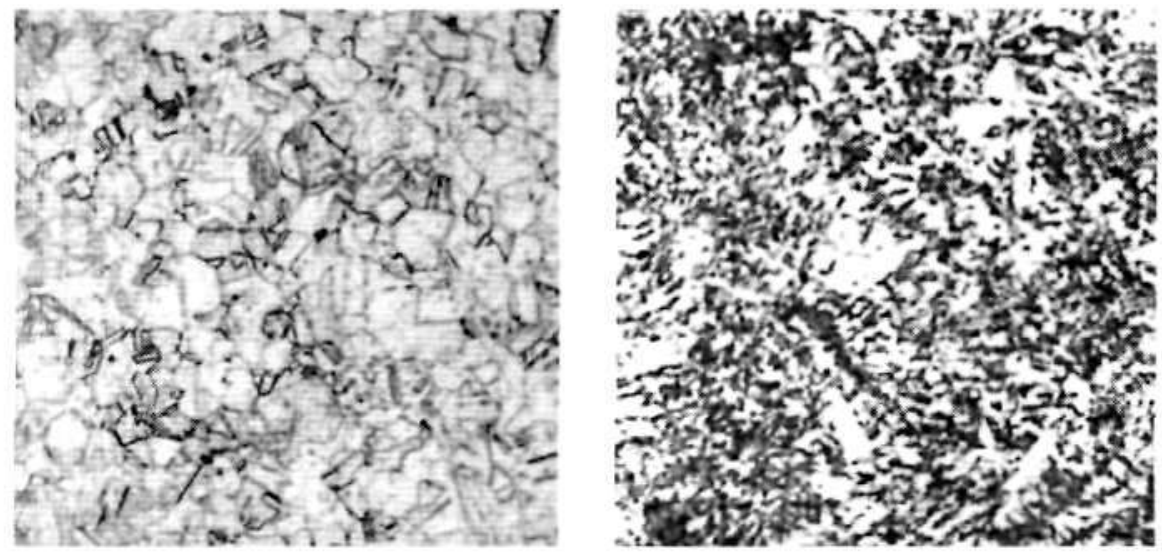

Figure 2. Transversal microstructure shape of SS-14301. Left parent SS, right, cold-drawn SS. X20.

Table 2. Mechanical properties of HSSS 1.4301.

\begin{tabular}{lllll}
\hline Type of steel & $\begin{array}{l}\text { Max load (UT) } \\
(\mathrm{MPa})\end{array}$ & $\begin{array}{l}\text { Yield strength } \\
(\mathrm{MPa})\end{array}$ & $\begin{array}{l}\text { Young } \\
\text { modulus (GPa) }\end{array}$ & $\begin{array}{l}\text { \% Reduct. } \\
\text { cross section }\end{array}$ \\
\hline $\begin{array}{l}\text { SS-(14301) } \\
(304)\end{array}$ & $1850 \pm 30$ & $1620 \pm 60$ & $227 \pm 11$ & $47.4 \pm 1$ \\
\hline
\end{tabular}




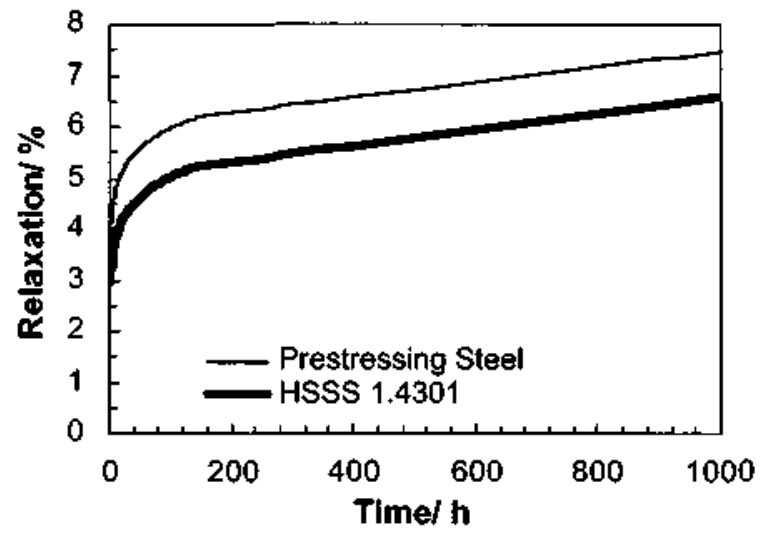

Figure 3. Relaxation behaviour of cold-drawn SS-14301 wire and conventional prestressing sted wire.
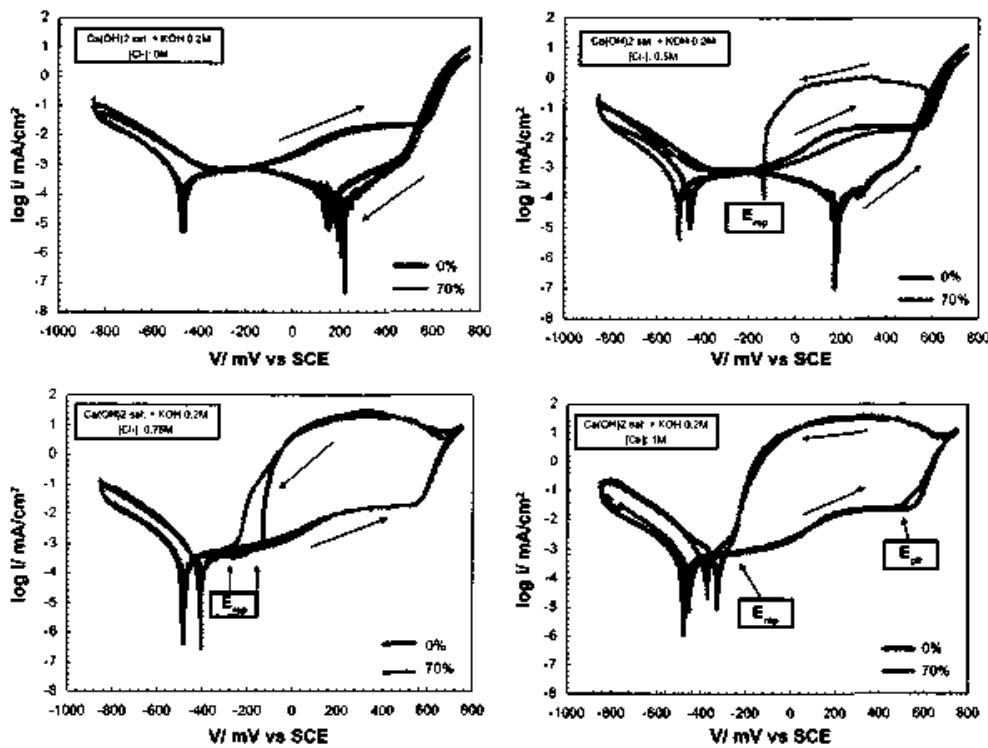

Figure 4. Influence of external load $(0,70 \%$ of maximum load $)$ in pitting corrosion.

drawn carbon steel was also determined and included in Figure 3. Relaxation was measured during $120 \mathrm{~h}$ and subsequently extrapolated up to $1000 \mathrm{~h}$ by means of a double-logarithmical regression, which is considered to be a conservative approach (Nürnberger et al. 1995). From Figure 3 it may be observed that the relaxation behaviour of the tested steel wires is similar. As expected the high initial relaxation is followed by attenuation with increasing time. The relaxation after $1000 \mathrm{~h}$ is in the same order of magnitude for both $14301 \mathrm{HSSS}$ and conventional prestressing steel. It should be stated that relaxation could be considerably reduced by use of stabilization treatments which should be objective of further investigation.

\subsection{Passivation-corrrosion performance of cold drawn SS1430I}

The cyclic voltammetries have allowed for identifying the capability of passivation of HSSS-14301 when exposed to alkaline media, such as that of concrete pores. In fact, from Figure 4 upper-left, the region of potentials where the passive layer is developed is well 
identified. Within the potential range from -400 to $+100 \mathrm{mV}$ (SCE) the residual current is very low, $<1 \mu \mathrm{A} / \mathrm{cm}^{2}$, indicating a low conductivity of the passive layer formed, also found in SS reinforcements using similar media (Abreu et al. 2004, Alonso et al. 2007, Veleva et al. 2002).

At more anodic potentials, a slight increase in current, up to $20 \mu \mathrm{m} / \mathrm{cm}^{2}$, is detected being identified as transpassive region due to the oxidation of $\mathrm{Cr}$ III into $\mathrm{Cr}$ VI oxides. Also transformation of $\mathrm{Ni}$ oxides is considered to occur at more anodic potentials near the region of oxygen evolution (Abreu et al. 2006, Veleva et al. 2002). At even more anodic potentials. above $+600 \mathrm{mV}$, the increase in current is due to the oxidation of water producing oxygen. The reverse of the curve in the cathodic direction shows that the current measured on the surface of the steel is even lower, and the Ecorr $>100 \mathrm{mV}$ vs SCE indicating a well developed passive layer. When the SS-14301 is under service load (70\% of the maximum load) the current recorded is the same, leading to the conclusion that the load does not affect the passivation process.

The presence of chloride in the alkaline system induces changes in the passive layer which depends on the chloride content, as may be deduced from Figure 4. The cold-drawn SS-14301 is able to resist the presence of chlorides in a concentration $0.3 \mathrm{M}$, even if exposed to external load, the passive layer is formed and gives similar response as in absence of chloride, not shown in Figure 4. When the chloride content in the system increases up to 0.5 the electrical response of the passive layer changes. At $0.5 \mathrm{M} \mathrm{Cl}^{-}$the risk of pitting initiation and propagation varies depending on the load. The cold-drawn HSSS $1430 \mathrm{I}$ may resist $0.5 \mathrm{M} \mathrm{Cl}^{-}$if there is no load, whereas under load the risk to initiate local attack is detected by an increase of current in the reverse curve. Probably the deformation induced by the load could be responsible of the lower resistance of the passive layer, this effect of the load on pitting corrosion has also been observed in conventional steel (Diaz et al. 2009, Guocheng et al. 2008). The negative effect of the load on pitting initiation is better observed as content of chlorides increases. At concentration of $0.75 \mathrm{M}$ the cold-drawn HSSS 14301 does not resist and the local break down of the passive layer is detected in both cases, with and without load. Similar observa. tions are made with $1 \mathrm{M}$, where a pitting potential, $\mathbf{E}_{\mathrm{pt}}$, is already noticed in the anodic scan at $+500 \mathrm{mV}$ SCE. Once the passive layer is broken a region with high current is recorded that in the reverse process decreases at a specific potential, identified as repassivation potential, $\mathrm{E}_{\text {ren, }}$, indicative of the capability that a specific pit can have to repassivate. At higher concentrations of chlorides the $\mathrm{E}_{\text {rep }}$ moves to more negative values suggesting that the repassivation of the pits is more difficult to occur.

\subsection{Stress corrosion risk of clod-drann SS-14301}

Once determined the risk of pitting corrosion of HSSS-14301, slow strain rate tests $\left(10^{-7} \mathrm{~s}^{-1}\right)$ carried out in those specific conditions where pitting can occur were considered. A pitting potential of $+300 \mathrm{mV}, \mathrm{SCE}$ and concentration of chlorides above $0.5 \mathrm{M}$ show that the pitting initiates during test loading, the currents recorded in Figure 5-right show an increase in current in presence of chlorides, while a progressive loss in ultimate strain of the steel is detected:

- This increase is not significant at $0.5 \mathrm{M} \mathrm{Cl}^{-}$. Pits do not propagate quick enough during SCC test and the mechanical properties are practically not affected, as show in Figure 5-left.

- At $0.75 \mathrm{M}$ a pitting initiation and propagation is observed after 20 hours. This pitting appears when the steel is in the elastic deformation as observed from cyclic voltammetries. The pits affect mechanical properties, as shown in Table 3 , by a reduction in ultimate strain and a slight decrease in tensile strength. The fracture of the steel seems to grow from the pitting region as observed from Figure 6.

- The $1 \mathrm{M} \mathrm{Cl}^{-}$initiates pitting at shorter ages and fast crack propagation leads to an important decrease of test duration, as shown in Table 3 .

These results indicate that for initiation of pitting and propagation of cracking a certain level of current is needed, that has to exceed more that 10 Coulombs $/ \mathrm{cm}^{2}$ to propagate pitting fast enough to induced loss in mechanical properties. 

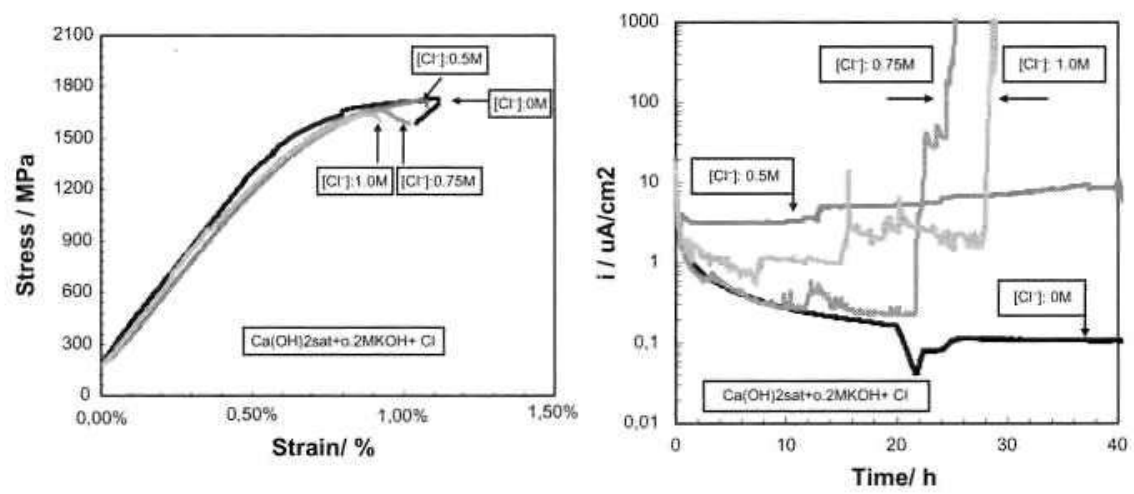

Figure 5. Stress-Strain curves from slow strain rate tests, (left), and current increase, (right), in cold drawn SS14301 in alkaline 13.2 with chlorides at polarisation pitting potential $+330 \mathrm{Mv}, \mathrm{SCE}$.

Table 3. Mechanical properties loss in cold-drown SS-14301.

\begin{tabular}{lllll}
\hline$[\mathrm{Cl}] / \mathrm{M}$ & UT/MPa & Strain/\% & Yield St./MPa & $\mathrm{t}_{\mathrm{r}} / \mathrm{h}$ \\
\hline 0 & 1750 & 1.24 & 1620 & 54.92 \\
0.5 & 1721 & 1.04 & 1715 & 53.43 \\
0.75 & 1666 & 0.94 & 1624 & 33.21 \\
1.0 & 1642 & 0.91 & - & 30.45 \\
\hline
\end{tabular}
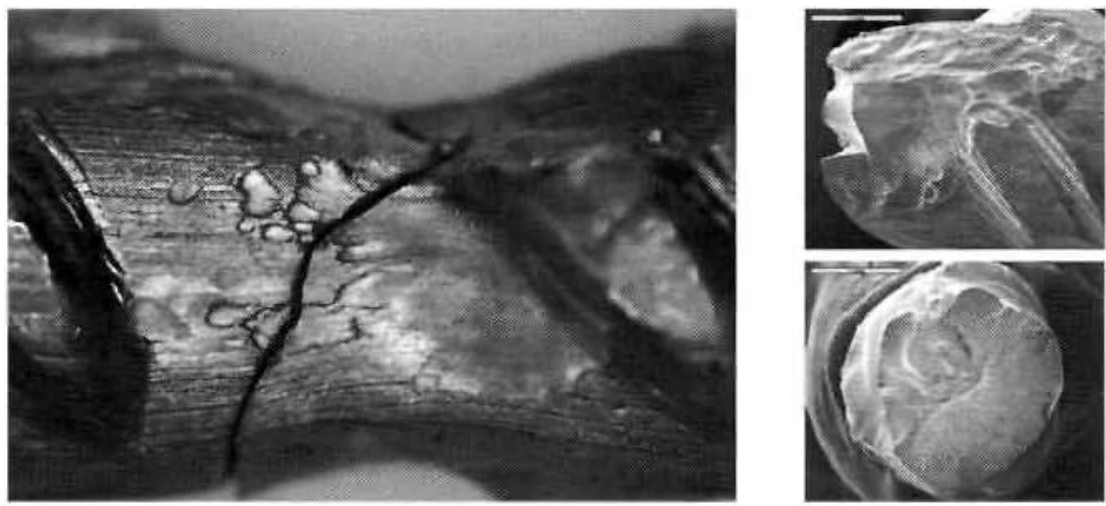

Figure 6. Fracture of cold-drawn SS-14301 after slow strain rate test in $0.75 \mathrm{MCl}$.
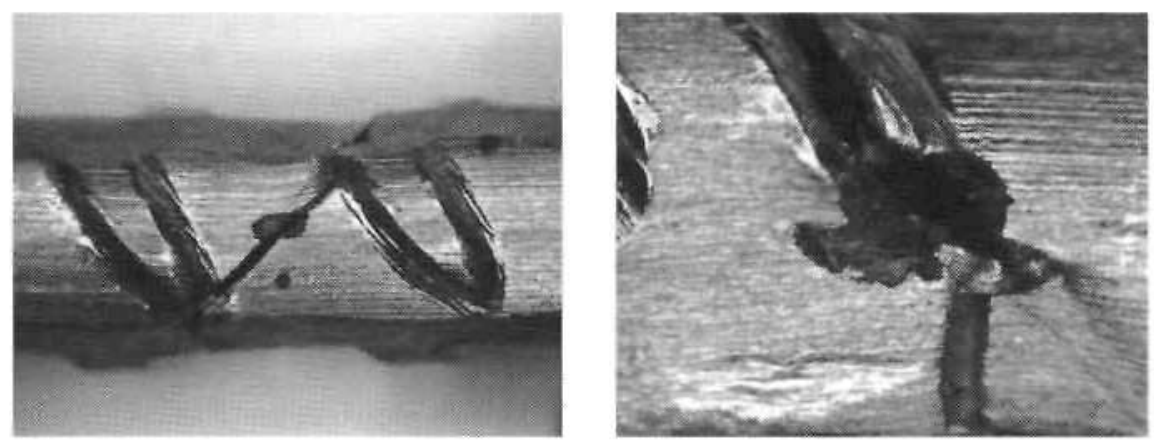

Figure 7. Fracture after HE in FIP test. 
The hydrogen embrittlement resistance carried out with F1P test shows that the cold-drawn SS 14301 resists $66 \mathrm{hrs}$, more than ten times than conventional prestressing steel ( Nürnberger et al. 2002) although less than austenitic stainless steel containing molybdenum (Nümberger. Wu Y. 2009). As shown in Figure 7-left the steel fracture is govened by a brittle behaviour. although the fracture initiates also in a pit, as shows Figure 7 -right.

\section{CONCLUSIONS}

- The obtained results reveal that HSSS $|430|$ is highly resistant to corrosion induced by chlorides in comparison to conventional prestressing steels, although pitting can be initiated in specific conditions at concentration above $0.75 \mathrm{M} \mathrm{Cl}$. The pitting developing is affected by the load of the system.

- Slow strain rate tests on the HSSS 14301 wires exposed to conditions that favor pitting show loss of their mechanical properties, like strain or ultimate tensile strength.

- The steel shows also bigher resistance to hydrogen embrittlement than conventional prestressing steel.

- The relaxation behaviour of the HSSS 14301 is similar to that of conventional prestressing steel.

\section{ACKNOWLEDGEMENTS}

Authors acknowledge the Spanish Ministry of Science and Innovation the economical support of the study through the project BIA 2007-65394 and INOXFIL S.A. for the manufacture of the HSSS. M. Sánchez also agrees her postdoctoral position support the Spanish Ministry.

\section{REFERENCES}

Abd El Meguid E.A., Malımoud N.A. \& Abd El Rehim S.S. 2000. The effect of some sulphur compounds on the pitting corrosion of type 304 stainless steel. Mater. Chem. Phw. 63:67.

Abreu C.. Cristobal M.I. Losada R.. Nóvoa X.R.. Pena G. \& Pérez M.C. 2004. High frecuency impedance spectroscopy study of passive films formed on AISl 316 stainless steel in alkaline medium. J. Electoranat. Chom. 572: 335 .

Abreu C.. Cristobal M.J., Losaida R., Nóvoa X.R.. Pena G. \& Pérez M.C. 2006. The effect of Ni in the clectrochemical properties of oxide layers grown on stainless steels. J. Electroct. Act. 51: 2991.

Alonso C. \& Recio F.J. 2007. Aceros inoxidables de alta resistencia mecánica en medios alcalinos con cloruros. Anates de Mocintica de factura: 649-654.

Alonso C. et ill, 2009. New materials and systems for prestressing strustures. Action Cost 534. Chapter 1 . New: materials.

Ameer M.A.. Fekry A.M. \& El-Taib Heakel F. 2004. Electrochemical behavior of passive films on molybdenum-containing austenitic stainless steels in aqueous solutions. Electrochim. Acra 50:43.

Bautista A.. Blanco G., Velasco F.. Gutierrez A.. Palacin S., Soriano L. \& Takenouti H. 2007. Passivation of duplex stainless steels in solutions simulating chloride-contaminated concretc. Materides d Construcción 57: 17.

Castro P. Troconis O.. Moreno E. Torres-Acosta A.. Martinez-Madrid M. \& Knudsen A. 2002. Waterials Pedfomance NACE 4l(10): $50-55$.

Chen H., Guo X.Z., Chu W.Y., Gao K.W. Wang Y.B. Su Y.J. \& Qino L.J. 2003. Martensite calused by passive film-induced stress during stress corrosion cracking in type 304 stainless steel. $M a t . S$ c: Engine ring 350 : 122.

Diaz. B., Freire L.. Novoa X.R. \& Pérez M.C. 2009. Electrochemical behaviour of high strength stee] wires in the presence of chlorides. Elcotoh him. Actu $54: 5190$.

Escudero M.L.. Garcia-Alonso M.C.. Capilla F. \& González J.A. 2602. Study of the corrosion resistance of stainless steel in solution simulating concrete. In: $15 \mathrm{~h}$ international comosion comgress. Granada, Spain. 
Fossati A., Borgioli F., Galvanetto E. \& Bacci T. 2006. Corrosion resistance properties of glow-discharge nitrided AISl $316 \mathrm{~L}$ austenitic stainless steel in $\mathrm{NaCl}$ solutions. Corros. $\$ c i .48: 1513$.

Garcia-Alonso M.C., Escudero M.L., Miranda J.M., Vega M.I., Capilla F., Correia M.J., Salta M., Bennani A. \& González J.A. 2007. Corrosion behaviour of new stainless steels reinforcing bars embedded in concrete. Cement and concrete research 37: 1463.

Guocheng L., Haidong C.. Chunchun X. \& Zonghu H. 2008. Efect of strain and chloride concentration on pitting susceptibility for type 304 austenitic stainless steet. Chinese Journal of Chemical Engineering 16: 314 .

Hewitt J. \& Tultmin M. 1994. Corrosion and stress corrosion cracking performance of stainless steel and other reinforcing bar materials in concrete. In: Swamy RN, editor. Corrosion and corrosion protection of steel in concrete. Sheffield Academic Press: 527-539.

Klingghoffer O.. Forlung T., Kofoad B., Knudsen A., Jensen F.M. \& Skovsgaard T. 2000. Practical and economical aspects of application of austenitic stainless steel, AISI 316, as reinforcement in concrete, in: J. Mietz, R. Polder \& B. Elsener (Eds.), Corrosion of reinforcement in concrete, European Federa. tion of corrosion, IOM Communications, London: 121.

Knudsen A., Jensen F.M., Klinghoffer O. \& Skovsgaard T. 1998. Cost-effective enhancement of durability of concrete structures by intelligent use of stainless steel reinforcement. Conference on corrosion and rehabilitation of reinforced concrete structures.

Mietz J. 2001. "Corrosion behaviour of stainless steels for use in ground anchors". Proc. of the 3rd International Conference CONSEC'OI-Concrete under Severe Conditions, Vancouver, Canada.

Nürnberger U. (editor). 1996, Stainless steel in concrete. State of the art report, Publication no. 18, Institute of Materials, London, UK.

Nürnberger U. 1995. Korrosion und Korrosionsschutz, Band 1Bauverlag GMBH, Wiesbaden und Berlin.

Nürnberger U. 2002. Corrosion induced failure mechanisms of prestressing steel. Mater Corrosion 53: 591.

Nürnberguer U. \& Wu Y. 2008. Stainless steel in concrete structures and the fastening technique. Mater. Corrosion 59: 144-158.

Sorensen B., Jensen P.B. \& Maanhn E. 1990. The corrosion properties of stainless steet reinforcement In: Page C.L., Treadaway C.K.J. \& Bamforth P.B., editors. Corrosion of reinforcement in concrete. Elsevier Applied Science: 601-610.

Veleva L., Alpuche-Aviles M.A., Graves-Broo K.M.K. \& Wipf D.O. 2002. Comparative cyclic voltametry and surface analysis of passive films grown on stainless steel 316 in concrete pore model solutions. I. Electroanal. Chem 537: 85.

Wu Y. \& Nürnberguer U. 2009. Corrosion-technical properties of high-strength stainless steels for the application in prestressed concrete structures. Materials and Corrosion 60. 